\title{
Epistemology, Structure and Urgency: the Sociology of Financial and Scientific Journalists
}

\author{
by Geoff Cooper and Mary Ebeling \\ University of Surrey; Drexel University
}

Sociological Research Online, Volume 12, Issue 3,

$<$ http://umw. socresonline.org.uk/12/3/8.html>

doi:10.5153/sro. 1558

Received: 19 Dec 2006 Accepted: 18 May 2007 Published: 30 May 2007

\begin{abstract}
This paper, which examines the work of journalists in one field, argues for the value of including journalists' own understandings and practices in analyses of the role of the media. Moreover it suggests that, in this field, there may be more commonalities between the practices of journalism and social science than is commonly supposed.

The paper is based upon a set of interviews with scientific and financial journalists, covering their interpretations of nanotechnologies and their development. Whereas much of the social scientific work to date in this area has been concerned with the public understanding of science, and the role that journalism plays in relation to this, our study addresses the parallel issue of how, in a field characterised by high levels of commercialisation, potential investors get information and make judgments about particular applications, and the extent to which journalism plays a key role in this process. Here, we focus not primarily on the ways in which the media frame understandings of a complex technology, important though they may be, but on the practical epistemological strategies that journalists employ to make sense of it.

We argue that journalists can be seen to be engaged in epistemological strategies that are analogous to those of sociologists, and that this dimension is too easily missed by approaches that, for example, recommend that the correct unit of analysis should always be journalism rather than journalists. We conclude by suggesting that, whilst the general applicability of our argument to other fields of journalism is necessarily an empirical question, our approach may have more general significance for debates about the critical role of social science.
\end{abstract}

\section{Keywords: Epistemology, Fields, Financial Understanding of Science, Nanotechnology, Sociology of Journalists, Scepticism, STS}

\section{Introduction: journalism, science and social science}

1.1 The extent to which the media are seen to have a critical and increasingly problematic role in the production and dissemination of academic knowledge may be gauged by the fact that the issue has been treated as a matter of urgent concern beyond the boundaries of those fields, such as media studies or science and technology studies, for which it clearly has immediate relevance. Both Derrida and Bourdieu for instance - prominent figures within philosophy and sociology respectively, with broad intellectual interests not only devoted attention to the general question of the dominance of the media within, and their effects on, public discourse, but more specifically addressed themselves to some of the limitations that the media impose on academic knowledge (Derrida, 2002; Derrida and Stiegler, 2002; Bourdieu, 1998 and 2005).

1.2 For both, an understanding of these problems presupposes an analysis of the relation between, to use Bourdieu's terminology, the fields in question. Thus for example, Derrida argues that the fact that each has its own and radically distinct rhythm underlies the difficulties that 'intellectuals' have in contributing to public discourse: " $t$ ] he one thing that one cannot accept these days - on television, on the radio, or in the papers - is an intellectual taking his time, or wasting other people's time" (Derrida, 2002: 89). The intellectual may have to choose between an acceptance of the trivialisation that the media's faster rhythm imposes, or silence $^{[1]}$. Bourdieu (2005: 45) makes a similar point, but his analysis of the relation is primarily formulated in terms of social structural differences between the respective fields (see below). More specialised empirical studies of media practice have also focused on this relation considering, for example, the extent 
to which the different occupational cultures of journalism and science has an effect on how the latter comes to be reported (Peters, 1995). In each case, the relation is the key object of analysis, and the reason for analysing it is in order to illuminate how and why knowledge becomes framed in particular ways by the media.

1.3 This emphasis on the framing of knowledge (of various kinds) finds its counterpart in media studies, in studies of public opinion and its formation and, a key point of orientation for this article, in science and technology studies (STS). The role of journalism in the mediation and dissemination of scientific knowledge is of course not a new area of study for STS (see Lewenstein, 1995, for a review), nor is it unexplored in the more particular context of nanotechnology, the topic that forms the basis of this article ${ }^{[2]}$. Indeed, in considering issues pertaining to the public understanding of science - which is probably the central concern of STS work on nanotechnology (see for example Barnett et al, 2006) - some attention to the role of the media is unavoidable, and consideration of its framing of knowledge claims indispensable ${ }^{[3]}$. If we are to understand the relationship between scientific claims and agendas, and public understandings and concerns, including perhaps the problematic political and moral dimensions of this relationship, then there is clearly considerable value in examining the particular ways in which media reports frame science; and important work of this kind has been done in relation to nanotechnology ${ }^{[4]}$.

1.4 To the extent that this article, and the research of which it is a element, focuses on the part played by journalists in the reporting of nanotechnology, it belongs to this latter body of work. It is based on a relatively small-scale research project that ran over the course of 15 months during 2005-2006 and investigated the relationship between news sources - scientists and PR companies - and journalists, and comprises interviews, ethnographic observation and analysis of documents ${ }^{[5]}$. Twenty-three people, professionals in financial journalism, venture capital and angel investing ${ }^{[6]}$, PR and marketing, science entrepreneurship and nanoscience were interviewed using in-depth, open-ended methods. Here, we concentrate on data from the intervews with eight journalists. However, we would like to draw attention to two aspects of our focus, one substantive and one analytical: the first of these distinguishes it from much of the relevant work to date in STS (on the media, the public understanding of science, and nanotechnology); the second, we suggest, provides an important complement to dominant analytical approaches to the media, not just within STS but within social science more generally.

1.5 In the first place, whilst our interest is in the understanding of this particular technology (or technologies), it is not in the public per se but in a specific sector, namely finance. We wanted to know more about the ways in which, within a field characterised by high levels of commercialisation, potential investors get information and make judgements about the viability of new nanotechnology applications and companies. We were especially attentive to the role of journalists (and other actors, particularly those in PR and marketing) in the mediation and dissemination of scientific knowledge, as journalists' copy may be part of the basis for such judgements. Since financial investment plays a key role in the development of this technology, which may be taken as a privileged exemplar of widely noted tendencies in contemporary knowledge production (Gibbons et al 1994; Nowotny et al 2001; Etzkowitz and Leydesdorf 2000), it seems opportune to look a little more carefully at this particular channel of communication in shaping what we can call the financial understanding of science ${ }^{[7]}$. We spoke to eight print (including web based) journalists, six of whom cover science and technology for financial publications, one of whom covers science and technology for a news wire service, and another who covers finance and business for a science publication. Three of the journalists had science backgrounds, with undergraduate degrees in physics, biochemistry, or other sciences, and came to journalism after their science training. Of the remaining five, three came from journalism backgrounds, and two came from business backgrounds with no previous training in journalism.

1.6 Secondly whilst, like Derrida and Bourdieu, our analytical interest is in the relation between different fields, we do not present an analysis of the ways in which the media frame knowledge claims. Certainly, although we are not looking at the difficulties that 'intellectuals' working in the humanities have in being properly heard via the media, there are some important points of resonance between some of our findings and Derrida's and Bourdieu's assertions, including the urgent rhythm of media work alluded to above. However, in Bourdieu's analysis in particular, journalists themselves have a shadowy presence at best. There are good analytical reasons for this, for he argues that to talk of journalists rather than journalism is to risk allocating responsibility to individuals for problems that are structural, and missing the realities of power that structure the field within which individuals move (Bourdieu, 2005: 41-2). We would also note at this point that Bourdieu's formulation of the political, social scientific and journalistic fields is one characterised by competition: all three, which have their specific logics, "lay claim to the imposition of the legitimate vision of the social world" but are also sites of internal conflict, and structured in terms of different forms of capital and prestige (ibid: 36 ). One problem here is that a rather deterministic model emerges in which the work and practical reasoning that journalists employ are nowhere to be seen, since they are seen to be "caught up in structural processes which exert constraints on them such that their choices are totally 
preconstrained" (Bourdieu, 2005: 45). It can indeed be argued that this is not characteristic of Bourdieu (Benson and Neveu, 2005); but, even if seen as a slip in this case, such a one sided picture (which can be found in many other parts of the social science literature) suggests the possible value of a study of journalists, and their modes and strategies of interpretation and action, the focus of this article.

1.7 That said, our formulation of this approach was not primarily derived from a reading of the extant literature but from the research itself. Our analysis began by exploring the journalists' position and concerns, since our hunch was that the understanding of this technology or set of technologies would be a practical and salient problem for them - and indeed for some of their readers who are key actors but lurk just offstage for much of this particular paper - since such an understanding is presumably crucial for any assessment of financial viability or risk ${ }^{[8]}$. (However the analysis indicates this presumption to be incorrect in some respects, as will be noted below.) In other words, and in this respect in line with an important strand of ethnomethodological thinking, we chose to build the analysis on some of the practical epistemological problems of participants, rather than make the latter the objects of analysis; we note for example the relevance of Pollner's (2002) discussion of the deflation of the analyst's position in certain online contexts, and Lynch's more general endorsement of the value of respecifying epistemological issues as 'epistopics' - matters of practical concern in particular settings (Lynch, 1993). In taking such a line, we have found a number of commonalities between the concerns, orientations and practices of these journalists and social scientists, which parallel those found among science journalists and scientists by Nelkin (1987: 102-103). We argue that taking this perspective usefully highlights journalists' reflective practices as active agents; and that, in this field, these practices include the use of epistemological strategies that are analogous to some of those used in STS and in sociology.

1.8 A methodological approach of this kind is not without its limitations. In the first place, the objection may legitimately be made that concentrating on explicating journalists' own analytical work in this way precludes the possibility of a sufficiently critical sociological analysis. Our argument here, to which we return in the conclusion, is that whilst our analysis may be limited in this respect, it is justifiable because, as noted above, it draws attention to an important aspect of practice that might otherwise be missed. However, in the second place, it is important to acknowledge that the analysis presented in this paper is based primarily on our respondents' accounts of their work, and therefore that the practices and strategies to which we draw attention are not the result of direct observation but features of those accounts. We maintain that suspending judgment on the some of the possible discursive features of their talk - including questions of veracity, performance, legitimisation for example - has value for the particular task of redressing an imbalance within the literature by putting more emphasis on journalists as reflective agents but, again, we would not wish to suggest that this could or should serve as the only model for work in this field.

1.9 The paper consists of, firstly, an analysis of our interviews with journalists, which underwrites our argument that journalists, in this sub-field, can be seen to be practising their own form of social science: we look at, in turn, their methods for evaluating claims, their sense of nanotechnology as a construct, and the ways in which they orient to different criteria (scientific validity, newsworthiness and financial viability). We then conclude by assessing the possible wider significance of this, considering the extent to which the validity of our argument might be restricted to the empirical domain in question, and relating our argument to wider questions about social science and its critical role. Whilst, as we have already implied, we think that certain critical approaches to journalism and its effects are not well positioned to capture these aspects of everyday journalistic practice, we see the value of our approach not as an all-or-nothing alternative, but rather as a useful, and possibly necessary, supplement.

\section{Journalists' strategies for evaluating scientific claims}

2.1 Latour and Woolgar (1986) noted that, instead of simply deploying available sociological and philosophical theories and epistemologies to analyse science, one could profitably use them as ways of characterising the understandings of scientists in their everyday work. Similarly, Gilbert and Mulkay (1984) showed that the contingent repertoire, which uses social factors to account for science, was one of the ways in which, in specified contexts, scientists discuss their work. An analogous displacement of theory is proposed here: that, in assessing or dealing with claims made for the technology, the journalists we interviewed routinely deploy a wide range of epistemological strategies, many of which map onto STS or social science positions.

2.2 In many cases financial and science journalists covering the emergence of the nanomarket do not have the expertise to make judgements about scientific claims, and any judgement has to be made in a rhetorically inflated context in which the novelty and significance of potential applications are being aggressively promoted. In order to distance themselves from the claims of their news sources, they may employ the kind of strategy defined by Tuchman (1978) as a 'web of facticity', that is, the reliance upon 
experts to speak to or verify the scientific and financial claims of nanotechnology. It is through the use of expert sources and their direct quotes on scientific claims that journalists are able to construct news information as "facts" (1978: 95). Hansen (1994) has suggested that science journalists not only make use of accredited scientific sources, but regard relying on press releases rather than actively seeking these sources out as poor journalism. In this setting however, there may be problems in locating appropriate trustworthy sources, as a science editor for a financial daily notes:

I don't think as a journalist you can really check out what is true, what you have to do is attribute it. [...] And there's no point in journalists ringing up some nanotech expert in a university and say 'I've been told this by a company' because the expert will say well how can I check any more than you? So I think checking is almost impossible, but attributing is what you do.

DD, 20/1/06

2.3 Here, the displacement of any evaluation of claims is even more pronounced than in Tuchman's formulation of a reliance on experts. In its abstention from judgement, this strategy has something in common with the axioms of explanation put forward by Bloor (1976). The validity of a claim is not actively endorsed; rather responsibility for validity is displaced by attribution.

2.4 Many see the complexity of the field, and the technologies within it, as posing particular epistemological problems both for investors and for journalists. One journalist on a trade paper, whose goal is 'the commercialisation of the technology' (NK, 9/5/06), suggests that this has been a problem for investors who moved from dotcom companies to 'the next big thing' only to discover that a potential investor in this market has to deal with a number of difficulties derived from the technical sophistication and heterogeneity of the technologies in question:

... the due diligence ${ }^{[9]}$ is much more significant than they thought, they don't have the technical expertise on staff, the marketplace is very confusing, there are a lot of competing technologies in a lot of arenas. So unless you're strong in the vertical ${ }^{[10]}$, it's hard to understand the technologies.

NK, 9/5/06

2.5 These represent difficulties for journalists as well as investors, and a number of strategies for addressing them are elaborated. For example, one US syndicated online columnist deals with the problem of which source to trust by using as many data sources as possible:

Well, one I'm not a reporter, I'm a columnist, so I'm allowed to express my own opinion. So I talk to everyone that I can about any subject.

DK, 19/1/06

2.6 He outlines what we might, perhaps loosely, call a strategy of triangulation in which using multiple sources, in this case differentiated in terms of financial expertise, will rule out the possibility of taking a partial view of the phenomena of interest.

2.7 However, there remains a problem of how much credence to give to individual sources. Here, what Bourdieu (2005) calls cultural capital can play an important role. In the first place science journalists rely on the reputations of the science publication or upon the peer-review system to verify the science (Hansen 1994; Nelkin 1987), as the science reporter at a financial news magazine told us:

But then what we're doing is we're relying on the journal themselves to have circulated this to the relevant people [the science has been peer-reviewed] and now obviously with Nature or Science you can rely on them to have done that, if it's the Journal of I've Never Heard of It Before then you have to be a bit more careful.

OM, 30/6/06

2.8 The cultural capital of the paper itself may also play a significant role. One reporter on a financial daily paper discusses how he evaluates information in terms of stages. Again, he notes the impossibility of direct verification of scientific claims, and explains that in the first instance, where information is likely to come from a PR company, an initial judgement is made on the basis of trust built up over time with particular sources. It is notable here that journalists are involved in establishing relationships with trusted sources as Hansen (1994) has argued, but that the latter may include PR companies as well as scientists. Secondly, where information looks promising, the company is contacted and spoken to 'on the record': a willingness to go on record to a reputable paper in itself provides some guarantees since: 
RE, $17 / 2 / 06$

2.9 As indicated, the need for trust is mutual, as the paper needs to preserve its credibility as a paper of record. Clearly the status of a newspaper's reputation is essential to this process, and a relatively privileged position in the journalistic field underwrites the viability of the evaluative strategy. It is also notable that other parties such as, in particular, PR companies, are engaged in building up their credibility - in a manner reminiscent of Latour and Woolgar's (1986) 'cycles of credit', adapted from Bourdieu - and this can act as a countervailing force to the high levels of exaggeration and hyperbole within the field. PR companies may be involved in pro-actively promoting a product or company, but their future efficacy may be compromised if they are perceived as unreliable by journalists or by their readers.

2.10 There are other ways in which PR companies may, perhaps surprisingly, emerge as reliable sources. A journalist on a US specialist science weekly describes in general terms how to find trusted sources in these terms:

I don't have any journalistic training, official training, but this is the sort of theory that I've adapted to myself is to essentially not to trust anyone and to assume that everyone has an agenda.

$\mathrm{KH}, 20 / 1 / 06$

2.11 He goes on to say that, given the existence of agendas, he tends to trust scientific sources more, even though the ideal of the objective, value-free scientist is 'nonsense, we know that people've got egos and financial issues' (KH, 20/1/06). However, PR sources can also be of value precisely because their interests are relatively transparent. His general approach is to explain particular claims, scientific or financial, with reference to the (presumed) causal influence of actors' motivations and interests: in other words, to deploy an analytical strategy analogous to the strong programme's invocation of social interests (see Barnes, 1978; and, for a critical view, Woolgar 1981). The more specific assertion about PR resembles, paradoxically perhaps given the author's political and moral articulation of the epistemology in question, Sandra Harding's (1996) notion of strong objectivity, in which the unattainability of a neutral form of objectivity is replaced by a form of knowledge which does not try to efface its social location or political agendas but instead makes them explicit as a way of achieving rigour.

2.12 Bourdieu's colleague Patrick Champagne states that journalists 'are generally taken in by this game in the best of faith because it is explicitly designed to take them in; public relations agencies really do put themselves in the journalists' place, doing real news work for those always hurried social actors who are constantly going from topic to topic' (2005: 50). On the contrary, our data suggests that whilst PR exerts an undeniable influence, journalists are far from manipulated in this way; that (as Nelkin, 1987 noted) they know the role of PR is to shape and influence how the news story is told; and that, whilst they are indeed 'hurried actors', Champagne's formulation radically underestimates the terms of their reflexive engagement with the structural features of the PR-Press relationship. Moreover, a notable feature of their accounts is the extent to which they actively analyse social processes (of which they are supposedly unwitting victims) in similar ways to sociologists.

\section{Constructionist accounts of nanotechnology}

3.1 It has been widely acknowledged that there are definitional problems with the term nanotechnology, not least because of the diversity of potential applications that it encompasses, and a number of respondents focused on these problems. For example, one online columnist who covers the nanotechnology market stresses the interpretive flexibility of the field in the sense that different actors define it in different ways. In response to a question about sources and whether he ever speaks to financial analysts he notes that:

... in the last six months a couple of firms have started to put analysts dedicated specifically to the field and often they define it differently than I do. So you know a lot of people are still trying to figure out what does and doesn't constitute nanotech.

$\mathrm{KT}, 8 / 2 / 06$

3.2 For this columnist, nanotechnology is an identifiable field, but there are different ways of drawing and demarcating its boundaries, and these can be related to the interests of particular categories of actors. Other journalists, however, express more fundamental reservations about validity of the term in relation to the phenomena that it purports to describe. These are frequently formulated in relatively pragmatic terms how useful the term is - but often articulate an underlying scepticism in relation to the object itself.

3.3 In at least one case, reservations about the usefulness of the term have become virtually an editorial 
principle. A technology correspondent for a European News Wire service explains that it is at best an 'umbrella term' which not only attempts to capture too heterogeneous a range of technologies, but also has more specific limitations, for example:

\author{
The entire semiconductor industry is now submicron. So it's all nanotechnology. So we never \\ use it. \\ $\mathrm{MH}, 23 / 6 / 06$
}

The term, in other word, also lacks descriptive precision in some of the subfields for which it is ostensibly most relevant.

3.4 A further reason for its perceived limitations, expressed by a number of respondents, concerns its status as a label under which companies may trade. More than one journalist sees the term as misleading because it is possible for companies to fraudulently present themselves as engaged in nanotechnology work; and, it is asserted, many are doing so. For one of them, working for a trade publication that sets out to promote the commercialisation of nanotechnologies, part of the problem is that the categorisation is given legitimacy by financial indexes that include such companies and thus confer a spurious identity upon them:

I think these indexes are serving a real disservice because there's not the education that's going around them. They can say 'Oh nano' but there are not enough public nano companies, it's not an index, those are the only, well there are only a few companies. And so it's frustrating for me to see the marketplace, or the public investor, you know the small investor get hoodwinked into the idea that 'oh hey here's a nano index and isn't this exciting'. NK, 9/5/06

In this case the term is problematic because - and the associated hyperbole is clearly a factor here - there are elements within its field of reference that should not be there: the referent, the object of description, lacks integrity.

3.5 If the solution for the problem of reference for this respondent is less inflated rhetoric and the availability of better information and education for the potential investor, for others the term is epistemologically incoherent and the object it describes does not exist, or does so only in the most banal sense. This science and technology correspondent (for an economics magazine) explains why she cannot distinguish between the financial potential of nanotechnologies and other areas of technology:

The only unifying thing about nanotechnology is it's stuff that's small. The definition is whatever it is less than 100 nanometers or whatever but if I were to say to you what are your impressions of a technology between the sizes of 1 metre and half a metre, do you see what I mean? OM, 30/6/06

For her, in other words, the problem is that the received definition is based upon a (Rylean) category mistake; the element that gives the term whatever coherence it has - scale - is not a sensible basis for grouping together a very heterogeneous set of technologies.

3.6 However, while there is widespread scepticism about the referential adequacy of the term or category, and the identity of the object it purports to describe, journalists recognise that, notwithstanding its epistemological limitations, it takes on a de facto reality that also make it inescapable. First, it acquires reality through its performance in particular contexts and settings; and secondly, the very hyperbole that both surrounds and obscures the term also produces certain effects that cannot be ignored.

3.7 The Lux Nanotech Index, for instance, is regarded by some respondents as conferring a spurious identity upon a group of very diverse companies. Those same respondents, however, acknowledge that such an index can have very concrete effects not least in terms of the perceptions of potential investors. Flows of money in this area, as in others, create their own realities. A syndicated online US columnist, talks about the absurdity of some companies being included in the nanotechnology category, but goes on to comment:

But if pure play nanotech companies [11], because hey everybody's investing in the stuff, it's a research and development expense but they're all getting roped into it, if they go off and get hot you will see all kinds of investment flow that way [...] So if you create enough buzz, institutions [i.e. institutional investors] will come.

DK, 19/1/06

The category is performative and as such creates its own (financial) reality. However it is an unstable 
reality: part of his concern is that investors may get impressive returns on their money, but that since the level of understanding of the nature of this 'field' is poor, the market is potentially risky.

3.8 Similarly another journalist, from a specialist science weekly, alludes to the fact that whilst nanotechnology 'doesn't exist' (KH, 20/1/06), and the mismatch between expectations and reality is a matter of concern for him, he keeps going to conferences on it to see if there are any good stories to be written: the conferences, by implication, preserve the category. The same phenomenon can be observed at STS conferences, not to mention papers that address the whole field rather than specific areas of application.

3.9 If the hyperbole surrounding the technology is recognised and commented on by all respondents, many point to the fact that a 'buzz' is something that cannot be completely ignored. We have already noted that the existence of the category, and the buzz that surrounds it can create effects in terms of flows of investment. An online columnist who covers the nanotechnology market suggests that this also takes place at the policy level:

I think hype does play a useful role, at least in nanotech it has. Without it I don't think the U.S. government and other governments around the world would have decided to invest the billions that they're now investing into a basis in the field.

$\mathrm{KT}, 8 / 2 / 06$

3.10 One important factor in this respect is the increasingly prominent role of PR. Whereas journalists might want simply to avoid the large amounts of PR copy with which they have to deal, on the grounds that it is of limited factual value and prone to exaggeration, the fact that very little information now comes from any other source means that this is not viable. Whilst we have contested the view that journalists are unwittingly manipulated by PR, there is no doubt that its presence and significance are unavoidable in this sphere. As one journalist on a financial paper puts it:

... [S]o the PR industry is very important even though sometimes we'd like to get away from it because it is a little bit formulaic, in practice you can't. RE, 20/01/06

Interestingly, however, this journalist goes on to say that the polarised views of nanotechnology (as the future, or empty hyperbole) act as a disincentive to write about it since it is difficult to avoid alienating one camp or another.

\section{Claims, stories and investments}

4.1 The discussion thus far has focused on epistemological judgements that are made about nanotechnology, and noted the significance of some of the rhetorical and performative elements that help constitute the category. Implicit in this is the recognition that, for journalists, scientific validity is not the only criterion of interest as has been noted in the literature on reporting science. Hansen (1994) for example has argued that the 'news value' criterion is no less important in reporting science than in other areas of journalism; while Anderson et al (1995) even note that the involvement of a celebrity can affect the framing of scientific story (about nanotechnology) no less than any other kind. Within our study, journalists may be concerned with what will make a good story, or with what will make a good investment. These criteria can be more distinct than might be supposed.

4.2 The requirement for a good story can, again, place the journalist in an ambivalent relation to inflated claims for the technology. KH discusses the difficulty of producing a good story in this context, noting that:

I think it's a tough job to communicate what's going on in nanotech now because you had a whole load of hype about the field which had now died down and actually a lot of nanotech is really, really boring, and it will remain really boring for years.

$\mathrm{KH}, 20 / 1 / 06$

4.3 Part of the assertion here is that once the spectacular claims have lessened, the mundane features of the technology can be more clearly seen. The narrative dilemma that this creates is a familiar one, and again it might be possible to map this onto a similar tension in social science literature: for instance, between texts that focus on the cultural imaginaries associated with nanotechnology (Hayles, 2004) and more sober empirical treatments within STS (Hunt and Mehta, 2006) ${ }^{[12] .}$

4.4 PR can play an important role in shaping the newsworthiness of a story, helping establish which news events are reported on, and ensuring that journalists help to maintain the velocity of the 'buzz' that it creates ${ }^{[13]}$. In a sense, this is a strategy too: if other papers are covering the story, in line with Tuchman's 
'web of facticity', then its ostensible truth status is reinforced. Kiernan has observed that, notwithstanding the stereotype of cut-throat competitiveness '[w]hen it comes to breaking news about scientific research, newspapers try to make sure to cover the stories that other newspapers cover. The goal is not to be different, but to be the same' (Kiernan 2003: 917). Bourdieu (2005: 44 et seq) makes a similar point about journalism more generally, arguing that competition for scoops has the effect of producing homogeneity. Because individual journalists and news outlets are loathe to be caught not covering an important science news story, cooperation between competing journalists themselves (through private agreements on what the story is, as well as giving each other leads on stories) and between journalists and PR professionals ensures that the same story tends to be reported, in a similar way, across media (Dunwoody 1986). This homogeneity in turn reinforces the achieved reality of the object, nanotechnology, despite its definitional problems and journalists' resistance to describing the diversity of nanotechnologies as an "industry".

4.5 The requirement to produce a good story may therefore take the form of an anxiety about missing the story as it is being constructed beyond the boundaries of the individual journalist's desk, and this can very effectively counteract any scepticism about claims made. As one respondent notes:

\author{
... [T]here is a whole other aspect to this is that if you have so many PR guns working for \\ you, there is a lot, there's so much coming to you, and it could be a big story among, so you \\ have to answer all those calls, you have to listen to them. \\ $\mathrm{MH}, 23 / 6 / 06$
}

4.6 The danger of missing the story, and being accountable to your editor for doing so, will therefore inform the ways in which the journalist deals with PR copy. Here, claims made for a technology may be in conflict with its narrative potential, and the journalist has to negotiate a way through these competing forces.

4.7 There is an interesting further side to this picture, which again suggests the limitations of seeing journalists as being simply manipulated by PR. Whatever one's misgivings about the way a piece of scientific news is 'spun', it then has to be sold to the journalist's editor at his or her newspaper - and indeed one of the complaints is that PR copy often does not give sufficient substance for effective internal spin. As one science journalist at a financial newspaper put it

They just see their job as selling the story to me but they don't realize that ...they have to give me enough of interest to get it through the next stage.

DD, 20/1/06

4.8 In this and the previous extracts, we can see that the internal features of the organisation of the newspaper, and especially the need to keep the editor happy in one way or another, are significant for journalistic practice (Hansen, 1994); whilst the requirement for good copy may be, as OM outlines in some detail, in tension with the need to resist the blandishments of a large, active and confident PR industry. A good story and a sober assessment of scientific validity may not coincide, and the journalist must find his or her own way of dealing with these conflicting requirements. However, it should not be assumed that this places journalists in a radically different position to social science: a similar argument has, for example, been advanced in relation to STS, suggesting that narrative qualities may be at least as important as factual status in an article's success (Woolgar and Cooper, 1999).

4.9 Similarly, one cannot assume - as the authors did in drafting the grant proposal for this work - that judgements about good investments imply judgements about scientific validity. On the one hand, something may be '. . . a wonderful technology but, you know what, it still might lose in the financial marketplace' (KT, $8 / 2 / 06$ ). On the other, a good investment need not necessarily be based on good science. A striking finding from our research as a whole, and borne out by interviews with journalists, is that venture capitalists and other investors looking for good short-term returns may be relatively uninterested in the scientific basis of claims (which in any case they are probably not competent to judge) as underlying long-term prospects, so long as the investment is in good shape at the point of exit:

Venture capital doesn't necessarily care whether or not a company succeeds in the long run. As far as I'm concerned, I know plenty of venture capitalists, they want to make sure the company succeeds at the point that they get their money back.

DK, 19/1/06

Here it is apparent that the temporal dimension plays a key role in judgements about the likely profitability of a nanotechnology company, and that the time frames for certain forms of investment and for judgements about scientific quality may be sufficiently different to limit their mutual relevance.

\title{
5. Conclusion: the sociology, and methodology, of journalists
}

5.1 We have focused on scientific and financial journalism and its place in the field of nanotechnology, 
concentrating not on the ways in which the latter is framed by the media, important though that may be, but on journalists' accounts of nanotechnology and their (reported) strategies for interpreting it. Our argument is that by looking at the practical epistemologies employed, we not only learn something about this particular arena, but also sketch out a line of inquiry that may have more general significance for social science.

5.2 Journalists in this field are engaged in work and forms of explanation that are in many respects analogous to those used by sociologists and scholars working in STS. To return to just one example, a story emerges of the way an object, nanotechnology, notwithstanding profound epistemological problems about its identity and coherence, becomes a reality va its performance in particular settings (cf Mackenzie and Millo, 2003). Thus, our suggestion is not only, following Lynch, that epistemological matters can often usefully be respecified as epistopics but also that, in this domain, there are particular symmetries between journalistic and social scientific practice which warrant further examination. We have touched on a number of these aspects, but even within this limited data set there are others: for example, the tension between objectivity and political engagement that exercised Weber and others is equally an issue for one of our respondents. 'Yeah I think that as a journalist ultimately you should try to change things. So but then you get into this issue of how do you report things accurately if you actually want to change things?' $(\mathrm{KH}$, 20/1/06).

5.3 Our findings have a number of points of contact with points made by Bourdieu, Champagne and others about the structures and constraints of the journalistic field. However, we have chosen to concentrate on journalists as active interpreters working within this field, and suggest that this is an important complement to work that sees them as simply constrained by social forces. Moreover, journalists are themselves highly competent and reflexive analysts of these forces. One respondent, for instance, reflects upon the different ways in which temporal pressures affect actors within the field depending upon their role and status: being a beat journalist on a daily paper renders one more vulnerable to corporate spin; seniority and (therefore) more time is needed to achieve critical distance:

\section{If you're just a beat journalist, you're just churning this stuff out, you don't have time to think oh hold on a second, we've heard this before, isn't this hard to believe. OM, 30/6/06}

5.4 This distinction is an important analytical one, reminding us - as has one of our referees - of the danger of generalising across a diverse field in which some categories of journalists may not have the opportunity or resources to be sceptical. Our general argument is that in order to understand the ways in which journalistic practice is shaped by the structure of urgency (cf Derrida, 2002: 298), and other forces, journalists' own understandings and strategies should be taken into account. In one sense of course this is a standard form of sociological argument; but we have also suggested that, in this sub-field, there are some specific similarities between the epistemological strategies, practices and analyses used by journalists and sociologists that merit further consideration. A 'sociology of journalists', in other words, should include the sociology that they themselves practice ${ }^{[14]}$. In the language of STS, there may be value in treating the two forms of analysis in a more symmetrical manner; or in Bourdieu's terms, the relation between the two fields does not, in this case, appear to be antagonistic.

5.5 The general applicability of some of our assertions about forms of journalistic practice is necessarily provisional, especially given the specificity of particular sub-fields of journalism (Champagne, 2005: 56 ). It is certainly the case that we have been studying and describing a highly specialised area of journalism, and we would not wish to claim that, for example, all journalists display the same kinds of analytical scepticism that we have sketched out here: it is possible, but remains a matter for further empirical study. However, if the substantive content of our findings cannot be easily generalised across sub-fields, we would nevertheless argue that an approach that begins from journalists' own understandings of their work can have value in other areas, even if its precise implications may turn out to be different.

5.6 In describing these journalists as not only active but in many respects sceptical interpreters of the technology, it may be argued that we are implicitly promoting a particular version of sociology, the stance it should adopt towards its object of study, and the extent to which that can or should be critical; we conclude with a brief consideration of this question.

5.7 Latour (2004) has argued that critique has 'run out of steam', and that social science needs to re-orient itself. There are a number of strands to his argument, but we highlight just one central one here. He states that the project of using constructionist forms of argument to undermine certainties of various kinds has been too successful, has become too easy: forms of analytical scepticism can now be routinely deployed by all manner of actors to question or undermine the supposed reality of particular objects, sometimes in the service of highly questionable arguments, including conspiracy theories. In a sense, he argues, critique has lost its critical edge, and his article is devoted to a reformulation of social science which would avoid both the impulse to debunk received ideas, contra the perceived naivety of social actors, and the privileging 
of one form of (social) analysis to explain away reality (cf Woolgar, 1981). Our argument has points of convergence and divergence with this proposal. We concur with Latour's caution about treating actors, here journalists, as naïve, and counterposing sociological descriptions in the light of which their understandings can be re-interpreted. However, we have found more structurally oriented descriptions to have analytical value, provided that they are not used to debunk actors' accounts, not least because the latter themselves contain important analytical insights. We have also found that analytical scepticism forms an important part of the everyday practice of scientific and financial journalists. However, we would hesitate to attribute this to the success of social scientists in spreading their constructionist messages: to make such a move would, we think, be to indulge in precisely the kind of sociological imperialism that Latour sets out to confront. Rather, and in the spirit of Latour's general line of argument, we see this similarity as prompting and indicating the value of critical reflection on forms of sociological argumentation and routine assumptions about their specificity and status.

\section{Notes}

${ }^{1}$ For reasons of space we leave to one side some of the connotations of 'intellectual'. Derrida's apparently highly gendered use of the term in fact occurs whilst developing a point about his own rhythm and form of response; nevertheless, it has been noted that term itself has a strong gender bias (see for example Cixous, 1992).

${ }^{2}$ Nanotechnology, or more accurately, nanotechnologies, spans a diverse range of science and technology unified by application at the nanoscale, or 100 nanometres or less. Generally it is the engineering at the nanoscale that is considered to be nanotechnology, but there are definitional struggles over the term. The plural, nanotechnologies, is a more inclusive term.

${ }^{3}$ The analysis of framing is not confined to the analysis of media constructions. Nisbet and Mooney (2007) for example, have suggested that scientists often frame their findings in inappropriate ways when communicating with the public, and that a better appreciation of the way citizens use and interpret information would improve communication and the general level of understanding of science within the wider population.

${ }^{4}$ See the special issue of Science Communication on 'Nanotechnology and the Public' (Lewenstein, 2005), and especially Stephens (2005), Anderson et al (2005) and Cobb (2005) for discussion of different aspects of media framing and its effects.

${ }^{5}$ The project is funded by the Economic and Social Research Council (ESRC), as part of its 'Science in Society' programme, award reference no RES-160-25-0047. The financial support of the ESRC, and the intellectual support and advice of the SiS programme director, Steve Rayner, are gratefully acknowledged.

${ }^{6}$ Angels are individuals using their money to invest in start-up companies in exchange for equity in the company, and usually share a large personal risk in the investment in the hopes of higher returns than from other types of investing. Most angel investments are between $£ 50,000$ and $£ 1$ million. Venture capitalists also invest in the early stages of a company and generally invest larger amounts than angels, from $£ 500,000$ and such investments also offer high returns (exceeding $20 \%$ ) and high risks. Venture capitalists can use their own money, but often it is money that has been pooled from several individuals, and there are a few publicly traded VC investment firms.

${ }^{7}$ The focus on finance is another key theme of recent work in STS, although our work has limited overlap with the central focus on the operation of markets in much of it: see for example, Callon (1998), KnorrCetina and Preda (2004), and, with a somewhat broader remit, Barry and Slater (2005).

${ }^{8}$ We note in passing that there is (complex) relationship to be explored between financial risk and the forms of risk more commonly focused on by social scientists. It is notable for example that there is a remarkable symmetry between the way that GM is held up as model and cautionary tale by both social scientists (see for example Einsiedel and Goldenberg, 2006) and actors with an interest in financial investment and returns, notwithstanding the rather different political and moral articulations to which that model is subject in each domain.

${ }^{9}$ Due diligence refers to research conducted by the investor, prior to investing capital, into all aspects of a company; these aspects include the underlying science and technology as well as financial fundamentals.

${ }^{10}$ Vertical, in this sense, refers to being a specialist in or expert on nanotechnologies. 
${ }^{11}$ Pure play, a term often used in the marketing and investing industries, means that a company's core business is solely focused on one area. In the context of our discussion here, pure play refers to companies whose core business is within the nanotechnologies field, be it, for instance, a company developing nanoparticles or a company providing services and equipment (such as atomic force microscopes) to those developing nanotechnologies. Since the emerging nanotech field is very small and diverse, there are relatively few 'pure play' nanotech companies.

${ }^{12}$ This is not to say that Hayles (2004) is an uncritical celebration of 'nanoculture', since it debunks some elements of the latter, but simply that its topical focus is indicative.

${ }^{13} \mathrm{As}$ Kiernan has shown, in his analysis of science reporting and press releases, one method used by PR companies to influence coverage amongst subscribing papers is the targeting of news wire services, such as Reuters or AP.

${ }^{14} \mathrm{~A}$ further dimension to the relationship between journalism and social science might be to consider how journalists assess sociological research: see for example Schmierbach (2005).

\section{References}

ANDERSON A, ALLAN S, PETERSON A, and WILKINSON C (2005) The framing of nanotechnologies in the British Newspaper Press, Science Communication, 27(1) pp 200-220

BARNETT, J, CARR, A, and CLIFT R (2006) Going public: risk, trust and public understanding of nanotechnologies, in Hunt and Mehta op cit

BARNES, B (1978) Interests and the Growth of Knowledge, London: Routledge

BARRY, A and SLATER, D (editors) (2005) The Technological Economy, Abingdon: Routledge

BENSON, R and NEVEU, E (2005) Introduction: field theory as a work in progress, in R. Benson and E. Neveu (editors) Bourdieu and the Journalistic Field, Cambridge: Polity

BLOOR, D (1976) Knowedge and Social Imagery, London: Routledge

BOURDIEU, P (1998) On Television and Journalism, London: Pluto Press

BOURDIEU, P (2005) The political field, the social science field, and the journalistic field, in R. Benson and E. Neveu (editors) Bourdieu and the Journalistic Field, Cambridge: Polity

CALLON, M (editor) (1998) The Laws of the Markets, Oxford: Blackwell

CHAMPAGNE, P (2005) The 'double dependency': the journalistic field between politics and markets, in R. Benson and E. Neveu (editors) Bourdieu and the Journalistic Field, Cambridge: Polity

CIXOUS, H (1992) Interview with Jonathan Ree, Talking Liberties, Channel 4, $6^{\text {th }}$ July

COBB, M.D (2005) Framing effects on public opinion about nanotechnology, Science Communication, 27(1) pp 221-239

DERRIDA, J (2002) Negotiations: Interventions and Interviews 1971-2001, Stanford: Stanford University Press

DERRIDA, J and STIEGLER, B (2002) Echographies of Television, Cambridge: Polity

DUNWOODY, S (1986) The science writing inner club: a communication link between science and the lay public, in S. Friedman, S. Dunwoody and C. Rogers, (editors) Scientists and Journalists: reporting science as news, New York: The Free Press, 155-169

EINSIEDEL, E and GOLDENBERG, L (2006) Dwarfing the social? Nanotechnology lessons from the biotechnology front, in Hunt and Mehta op cit

ETZKOWITZ, H AND LEYDESDORFF, L (editors) (2000) Special issue: Triple Helix, Research Policy, 29 (2) pp 109-330 
GILBERT, N and MULKAY, M (1984) Opening Pandora's Box: a sociological analysis of scientists' discourse, Cambridge: Cambridge University Press

HANSEN, A (1994) Journalistic practices and science reporting in the British Press, Public Understanding of Science, 3(2) pp 111-134

HARDING, S (1996) Rethinking standpoint epistemology: what is 'strong objectivity'? in E. Keller and H. Longino (editors) Feminism and Science, Oxford: Oxford University Press

HAYLES, K (editor) (2004) Nanoculture: implications of the new technoscience, Bristol: Intellect

HUNT, G and MEHTA, M (editors) (2006) Nanotechnology: risk, ethics and law, London: Earthscan

KIERNAN, V (2003). Embargoes and science news, Journalism \& Mass Communication Quarterly 80(4): 903-920

KNORR-CETINA, K and PREDA, A (editors) (2004) The Sociology of Financial Markets, Oxford: Oxford University Press

LATOUR, B (2004) Why has critique run out of steam? From matters of fact to matters of concern, Critical Inquiry, 30 (Winter) 225-248

LATOUR, B and WOOLGAR, S (1986) Laboratory Life: the construction of scientific facts, Princeton, NJ: Princeton University Press

LEWENSTEIN, B (1995) Science and the media, in S. Jasanoff, G. Markle, J. Peterson and T. Pinch (editors) Handbook of Science and Technology Studies, Thousand Oaks: Sage

LEWENSTEIN, B (editor) (2005) Special Edition: Nanotechnology and the public, Science Communication, 27 (2) pp 169-299

LYNCH, M (1993) Scientific Practice and Ordinary Action, Cambridge: Cambridge University Press

MACKENZIE, D and MILLO, Y (2003) Constructing a market, performing theory: the historical sociology of a derivatives exchange, American Journal of Sociology , 109 (1) pp 107-145

NELKIN, D. (1987). Selling science: how the press covers science and technology . New York, Freeman

NISBET, M.C and MOONEY, C (2007) Framing Science, Science, 316, p56

NOWOTNY, H, SCOTT P and GIBBONS, M (2001) Re-thinking Science, Cambridge: Polity

PETERS, H.P (1995) The interaction of journalists and scientific experts: co-operation and conflict between two professional cultures, Media, Culture and Society, 17 pp 31-48

POLLNER, M (2002) Inside the bubble: communion, cognition and deep play at the intersection of Wall Street and cyberspace, in S. Woolgar (editor) Virtual Society? Technology, cyberbole, reality, Oxford: Oxford University Press

SCHMIERBACH, M (2005) Method matters: the influence of methodology on journalists' assessments of social science research, Science Communication, 26 (3) 269-287

STEPHENS, L.F (2005) News narratives about Nano S\&T in Major U.S. and Non-U.S. Newspapers, Science Communication, 27(1) pp 175-199

TUCHMAN, G. (1978). Making News: A study in the construction of reality . New York, The Free Press

WOOLGAR, S (1981) Interests and explanation in the social study of science, Social Studies of Science, $11,365-94$

WOOLGAR, S and COOPER, G (1999) Do artefacts have ambivalence? Social Studies of Science, 29 (3) pp 433-449 